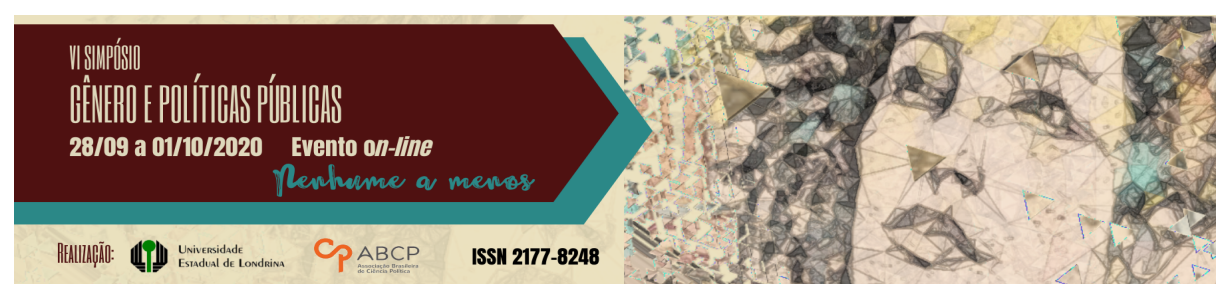

\title{
Difamação e pânico como estratégia discursiva: análise do discurso conservador sobre os direitos da comunidade LGBTQIA+
}

\author{
Marcelo de Souza Campos ${ }^{1}$; Marisse Costa de Queiroz ${ }^{2}$
}

\section{Resumo}

Considerando os direitos sexuais como um campo político, a presente pesquisa analisa os discursos dos grupos denominados de "contra-gênero", que afirmam existir uma "ideologia" ou espécie de "doutrinação" de gênero nas políticas de reconhecimento de direitos de minorias historicamente excluídas do acesso a direitos, tais como a comunidade LGBTQIA+. Essa pesquisa se propôs a mapear quem são, como se organizam e onde atuam essas organizações, para então descrever seus argumentos, fundamentos e teses, tendo por recorte os discursos produzidos acerca do tema da diversidade sexual e dos direitos LGBTQIA+. Utilizou-se o método dedutivo, por meio da análise bibliográfica e documental, com a abordagem descritiva e a discussão do problema realizada de maneira qualitativa. Foram sistematizados dados para contribuir com a compreensão dos discursos e a percepção sobre os Direitos Humanos de grupos historicamente excluídos, para se pensar em estratégias dialógicas de enfrentamento aos problemas criados por esses discursos.

Palavras-chave: direitos sexuais; gênero; ideologia.

\footnotetext{
1 Graduando do Curso de Direito da Pontifícia Universidade Católica, Campus Londrina/PR, Bolsista PIBIC PUCPR, e-mail: souzacamposmarcelo@gmail.com.

2 Mestra, professora no curso de Direito, orientadora do Projeto de Iniciação Científica (PIBIC) da Pontifícia Universidade Católica do Paraná, e-mail: marisse.queiroz@pucpr.br.
}

GT 19 - Sexualidade, gênero e políticas educacionais 


\title{
Defamation and panic as a discursive strategy: analysis of the conservative speech on the rights of the LGBTQ community
}

\begin{abstract}
Considering sexual rights as a political field, this research analyzes the discourses of groups called "counter-gender", which claim to exist an "ideology" or kind of "indoctrination" of gender in policies to recognize the rights of minorities historically excluded from access to rights, such as the LGBTQIA+ community. This research aimed to map who they are, how they organize themselves and where these organizations work, and then describe their arguments, foundations and theses, having as a cut out the discourses produced on the theme of sexual diversity and LGBTQIA+ rights. The deductive method was used, through bibliographic and documentary analysis, with the descriptive approach and the discussion of the problem performed qualitatively. Data were systematized to contribute to the understanding of discourses and the perception of human rights of historically excluded groups, to think about dialogical strategies to face the problems created by these discourses.
\end{abstract}

Keywords: sexual rights; gender; ideology

\section{Introdução}

O presente trabalho tem como tema uma análise dos conteúdos de discursos político-sociais de cunho conservador, selecionados segundo critérios metodológicos específicos, com a finalidade de descrever seus consequentes impactos frente à efetivação dos direitos sexuais, visando, especialmente, sua garantia face à comunidade LGBTQIA+. A problemática está diante da sustentação e propagação de ideologias conservadoras por meio de discursos que violam direitos e garantias fundamentais previstas na Constituição da República Federativa do Brasil de 1988 e nas normativas internacionais relativas aos direitos humanos, das quais o Estado Brasileiro é signatário.

O espaço político e social brasileiro sempre esteve marcado por antagonismos entre grupos e interesses. Movimentos conservadores sempre estiveram presentes influenciando regimes políticos, interferindo na legislação ou definindo políticas públicas. Geralmente 
esses movimentos se opõem a grupos que atuam politicamente na promoção avanços sociais e jurídicos que possuem perspectivas mais inclusivas e emancipatórias. A abertura democrática pós ditadura e a promulgação, em 1988, da Constituição Federal, possibilitou um crescimento de movimentos progressistas que começaram a ganhar força e visibilidade na luta pela defesa de direitos antes sequer discutidos, marcado pelo amadurecimento de inúmeros discursos em defesa da liberdade e da igualdade de gênero, especialmente em consideração à posição feminina.

Frente a esse contexto, estimulados especialmente pelo movimento feminista, outros movimentos indiretamente afetados pela desigualdade de gênero também passaram a compor a linha de frente em busca de igualdade e reconhecimento. Dentre esses movimentos, está o LGBTQIA+. Assim, questões relacionadas aos direitos sexuais e identidades de gênero, de forma geral, passaram a ser objeto de discussão de forma ampla na sociedade. Termos como direitos sexuais e reprodutivos foram consolidados em Tratados e Conferências Internacionais que geraram compromissos do Estado Brasileiro com o reconhecimento no âmbito nacional da garantia de direitos no campo da intimidade (nome, identidade, privacidade e diversidade sexual) e das relações familiares (casamento, união estável e parentalidade independente da orientação sexual ou identidade de gênero). O reconhecimento desses direitos repercutiu em outros campos do direito, tais como previdência social, registro público, saúde e educação, bem como no campo da responsabilidade civil e penal.

Esses avanços não vieram sem controvérsias e disputas de narrativas. Considerando que o avanço no campo dos direitos sexuais da população LGBTQIA+ é um campo em construção que contesta imaginários e valores sociais arraigados, no contexto deste trabalho, propomos descrever os discursos socialmente construídos que advogam a tese de que estudos de gênero são ideologias lesivas. Os grupos contra-gênero negam os direitos sexuais como categoria dos direitos humanos, reconhecendo a aplicação das políticas públicas 
emancipatórias como sendo discursos ideológicos e doutrinadores que contribuem para a efetivação de um mecanismo de manobra social, que visa supostamente a "tomada do poder" pelos movimentos de esquerda.

Utilizando método qualitativo de análise de documentos, esta pesquisa visa analisar a produção discursiva considerando o posicionamento dos grupos contra-gênero sobre os direitos conquistados pela comunidade LGBTQIA+. A pesquisa selecionou grupos organizados (pessoas jurídicas) com atuação nacional e as publicações em sites dessas instituições no ano de 2019.

Por fim, é importante frisar que o presente artigo é resultado da pesquisa de Projeto de Iniciação Científica (PIBIC), financiada pela Bolsa PUC, com vigência de um ano, ocorrida entre 2019 e 2020, realizada sob orientação da docente coautora.

\section{Os estudos de gênero}

Os estudos de gênero integram um campo teórico e epistemológico que questiona a premissa da existência de uma superioridade hierárquica do homem sobre a mulher em razão das diferenças biofisiológicas. No Brasil, essas reflexões se iniciam a partir da década de 1970, quando do ressurgimento dos movimentos feministas de "segunda onda", no contexto da luta política contra a ditadura militar, que se preocupava com o "fato de o país não ter uma 'tradição democrática', [...] de que a longa história de ditaduras e governos de exceção teria impedido que os brasileiros e as brasileiras tivessem uma prática democrática consolidada" (PEDRO, 2006).

Os aspectos biológicos e sexuais que distinguem os seres humanos se dão pela valorização de fatores culturais, os quais estabelecem distinções, diferenciações sociais, hierarquias e exclusões/discriminações que estão presentes nos discursos tradicionais (BUTLER, 2003, p. 26). Portanto, são estabelecidas normas 
(normalizações) que definem os comportamentos e modos de vida "corretos", "certos", "saudáveis", etc., em oposição a outros que são considerados como "errados", "pecaminosos", "patológicos", etc.

Os estudos de gênero têm demonstrado, em várias esferas, que essas construções sociais que normalizam e normatizam a diversidade em formas de se vivenciar a sexualidade, são baseadas numa heteronormatividades, a qual define e determina regras e comportamentos sociais em torno de uma coincidência necessária entre identidade, sexo biológico e desejo sexual. Dessa forma, todos os comportamentos, identidades de gênero ou vivências afetivo-sexuais que não se encaixem no modelo heteronormativo tendem a ser excluídos, negados, discriminados ou patologicizados.

Ao denunciarem essa construção social discriminatória, os movimentos feministas e LGBTQIA+4, nas últimas duas décadas, conseguiram avançar nos estudos de aspectos da sexualidade humana,

3 Termo que descreve situações nas quais orientações sexuais diferentes da heterossexual são marginalizadas, ignoradas ou perseguidas por práticas sociais, crenças ou políticas. Isto inclui a ideia de que os seres humanos seriam definidos sexualmente por duas categorias distintas, restritas e complementares: macho e fêmea. A partir dessa binariedade sexual rígida, observa-se a influência de diversas outras crenças e normas que, por exemplo, definem como "normais" e aceitáveis as relações afetivo-sexuais (namoro e relações conjugais) somente aquelas entre pessoas de sexos distintos; que cada sexo possui certos papéis e funções sociais inquestionáveis (p.ex., o mito do "instinto materno" e da "compulsão sexual" para os homens). Assim, sexo biológico, identidade de gênero, orientação sexual e papéis sociais deveriam, em tese, abarcar qualquer pessoa dentro dessas normas rígidas, que podem ser explícitas ou implícitas. Aqueles que identificam e criticam a heteronormatividade dizem que ela distorce o discurso ao estigmatizar conceitos desviantes tanto de sexualidade quanto de gênero e tornam certos tipos de auto expressão mais difíceis de serem vivenciadas sem estigmas ou violências.

${ }^{4}$ LGBTQIA+ é um acrônimo que busca inserir a representatividade de diversas formas de manifestação da sexualidade, divergentes da norma social estabelecida entre sexo biológico, concordante com a identidade de gênero e com a heterossexualidade do desejo. Segundo Interdonato e Queiroz, o acrônimo é amplo, abarcando formas de expressões afetivo-sexuais (orientação sexual), expressões e performatividades de gênero que rompem com padrões e normas sociais de como expressar feminilidade e masculinidade e pessoas que nascem com características sexuais biofisiológicas de pessoas não binárias, como os intersexuais, ou pessoas que não expressam atração sexual como os assexuais. No campo sociopolítico, a sigla visa demarcar as demandas dos sujeitos representados nessas denominações para afirmar direitos e reconhecimento no âmbito social e jurídico (INTERDONATO; QUEIROZ, 2017). 
reconhecendo-os como categoria dos direitos humanos. Termos como "direitos sexuais e reprodutivos" foram consolidados em Tratados e Conferências Internacionais 5 que geraram compromissos do Estado Brasileiro com o reconhecimento no âmbito nacional da garantia de direitos no campo da intimidade (nome, identidade, privacidade e diversidade sexual) e das relações familiares (casamento, união estável e parentalidade independente da orientação sexual ou identidade de gênero).

Nessa mesma perspectiva, Connel ensina que as relações de gênero são mutáveis e se renovam no tempo e tendo por raciocínio que esses estudos são dinâmicos, bem como se analisando categoricamente uma relação de gênero, sempre deve ser considerado o contexto em que os indivíduos habitam e a maneira como se relacionam com as demais perspectivas sociais (CONNELL; PEARSE, 2015, p. 153).

\section{Os direitos sexuais e reprodutivos como categoria dos direitos humanos}

Um conceito operacional importante, fruto dos estudos de gênero, diz respeito à definição e categorização dos direitos sexuais como um tipo específico de direitos humanos. Os direitos sexuais ${ }^{6}$ são definidos como a possibilidade de vivenciar uma vida sexual com

\footnotetext{
5 Os conceitos relacionados aos direitos sexuais e reprodutivos foram amplamente abordados e institucionalizados, por exemplo, em três conferências promovidas pela Organização das Nações Unidas (ONU), na década de 1990, sendo elas: Conferência de Direitos Humanos de Viena (1993), Conferência sobre População e Desenvolvimento do Cairo (1994) e a IV Conferência Mundial sobre a Mulher de Pequim (1995).

6 Importante destacar que essa categoria de direitos humanos se diferencia de outro conceito importante que são os direitos reprodutivos, que apesar de pertencentes ao campo de análise, tem fundamentos diversos. Direitos reprodutivos compreendem o direito básico de todo casal e de todo indivíduo de decidir livre e responsavelmente sobre o número, o espaçamento e a oportunidade de ter filhos e de ter a informação e os meios de assim o fazer, gozando do mais elevado padrão de saúde sexual e reprodutiva. Incluem o direito: a) individual de mulheres e homens decidirem livre e responsavelmente o número de filhos e os intervalos entre eles; b) de tomar decisões sobre a reprodução, livre de discriminação, coerção ou violência; c) de homens e mulheres participarem com iguais responsabilidades na criação dos(as) filhos(as); d) a serviços de saúde pública de qualidade e acessíveis, durante todas as etapas da vida. (PIOVESAN, 2003, p. 247).
} 
prazer e livre de discriminação, sendo que sua efetividade está relacionada com a promoção de liberdades e garantias que incluem o direito de decidir livre e responsavelmente sobre sua sexualidade sem intervenções externas; o direito de ter controle sobre o próprio corpo; o direito de vivenciar livremente sua orientação sexual, sem sofrer violência, discriminação e coerção; o direito à privacidade e o direito à saúde sexual, o qual exige o acesso a todo tipo de informação, educação e a serviços confidenciais de alta qualidade sobre sexualidade e saúde sexual, incluindo recursos tecnológicos quando necessários (PIOVESAN, 2003, p. 247).

Mesmo sendo categorias de direitos humanos, os direitos sexuais e os direitos reprodutivos possuem especificidades que os colocam na classificação de $3^{\mathrm{a}}$ e $4^{\mathrm{a}}$ geração ${ }^{7}$. São direitos definidos no campo das subjetividades ou individualidades de seus titulares, incluindo principalmente a possibilidade de tomar decisões (poder) e de ter acesso a recursos (políticas públicas) que apoiem essas decisões. Também devem ser analisados no contexto relacional dos indivíduos, considerando que a vivência da sexualidade nos corpos implica na existência desses corpos num universo social e politicamente mediado (CORRÊA; PETCHESKY, 1996, p. 149). Por estar inserida no contexto da

\footnotetext{
7 Conforme explica Lima (2003), classificar os direitos humanos em gerações ou dimensões, fazem parte da teoria geracional desenvolvida por Karel Kasak em 1979. Segundo essa teoria, os direitos humanos se desenvolvem em momentos históricos diversos, que vão se ampliando e complementando. Assim os direitos humanos de $1^{\mathrm{a}}$ geração estão relacionados às liberdades individuais, legado da revolução burguesa moderna, na qual o Estado não intervém na autonomia privada (obrigação de abstenção). A segunda geração diz respeito aos direitos sociais básicos, fundados no princípio da igualdade e que demandam prestações positivas do Estado. Os direitos de $3^{\mathrm{a}}$ geração estão relacionados ao princípio da dignidade da pessoa humana e às garantias existenciais dos sujeitos, surgidos após a $2^{\mathrm{a}}$ Guerra Mundial, relacionando-se a direitos e bens comuns à toda humanidade e à cooperação entre os povos. Apesar de controvertida, alguns autores apoiam a existência de uma $4^{\mathrm{a}}$ geração de direitos humanos, decorrente das conquistas da $3^{\text {a }}$ dimensão, que amplia essas três dimensões anteriores e inova na consolidação do direito de participação democrática (democracia direta), do direito ao pluralismo, do direito à bioética e aos limites da manipulação genética. Portanto, estão fundados na defesa da dignidade da pessoa humana contra intervenções abusivas de particulares ou do Estado, e fundamenta a teoria dos novos direitos decorrentes dos avanços científicos, informacionais (internet) e novas demandas ambientais.
} 
cultura, ou seja, por seu significado depender da mediação e valoração social, a sexualidade humana deve ser considerada também por mecanismos sociais que a constituem e a normalizam. Portanto, a vivência da sexualidade nos corpos individualizados tem uma dimensão histórica, social e política, ou seja, possui um caráter construído (SCHIOCCHET, 2007, p. 4).

Nesse seguimento, pode-se dizer que os direitos sexuais estão intimamente relacionados ao direito fundamental à saúde, contudo, possuem uma dimensão mais ampla, dentre elas o direito à educação sexual vista de forma positiva e abrangente. Por conseguinte, temas como sexualidade, saúde sexual, diversidade sexual, dentre outros, passaram a figurar nas políticas educacionais no Brasil como direitos subjetivos de crianças e adolescentes e como obrigação do Estado em promovê-los através da transmissão de saberes sobre esses temas. Essa formação é também fundamental para a democracia como sistema que promove a convivência a partir da diversidade e da pluralidade.

Mapeando as diferenças de perspectiva: estudos de gênero versus "ideologia de gênero"

Apesar dos estudos de gênero e das categorias jurídicas decorrentes desse conhecimento serem muito bem sustentadas pelos teóricos e teóricas do mundo todo, no Brasil, alguns grupos juridicamente organizados divergem desses posicionamentos. Desse modo, convém destacar duas vertentes sobre a problemática: a tese defendida pelos grupos "contra-gênero", que negam os direitos sexuais como categoria dos direitos humanos, em oposição à tese dos grupos "pró-gênero", que sustentam um discurso democrático e de caráter emancipatório, onde se valoriza o respeito, o diálogo e abre margem à diversidade sexual.

Historicamente, verificou-se que o pensamento defendido pelo primeiro grupo (contra-gênero) endossa vigorosamente inúmeros apelos morais contra a criminalização da homofobia e à igualdade de gênero. 
Utilizando-se do argumento de que há uma intenção de desestruturar as famílias tradicionais, os integrantes da "onda conservadora" passaram a sustentar discursos investidos de preconceito, intolerância e ódio, propagados disfarçadamente como teses categóricas, religiosas e nacionalistas.

Inclusive, sobre o instituto familiar, Maria Lúcia Silva Barroco (BARROCO apud FERREIRA, 2016, p. 3) ensina que:

A família é um dos alicerces morais do conservadorismo e sua função é a de manutenção da propriedade. A mulher exerce o papel de agente socializador responsável pela educação moral dos filhos; por isso, essa perspectiva é radicalmente contrária aos movimentos femininos, entendendo-os como elemento de desintegração familiar. A moral adquire, no conservadorismo, um sentido moralizador [...]. É assim que se apresentam sob diferentes enfoques e tendências, objetivando a restauração da ordem e da autoridade, do papel da família, dos valores morais e dos costumes tradicionais.

No que lhe concerne, Guilherme Gomes Ferreira entende que a preocupação desses movimentos gira em torno da adesão de crianças e jovens ao que ele denomina de "moda da homossexualidade e do feminismo", de modo que essas deixem de valorizar as tradições e a hierarquia familiar e passem a defender, futuramente, "ideologias" de esquerda.

Verifica-se, portanto, no entendimento patriarcal, que as convicções idealistas de "família inabalável" devem prevalecer sobre qualquer aspecto. Isso decorre, nas palavras de Sergio Gomes da Silva, do medo masculino de [...] tornarem-se homossexuais e [...] de pôr a prova o seu sexo forte. Os homens tiveram que cultivar mais do que nunca a sua masculinidade e a sua virilidade, caracterizando também a primeira crise da identidade masculina" (SILVA, 2000, p. 4). 
Nessa lógica, sabe-se ainda que masculinidade é encarada como soberana se comparada ao universo feminino, considerado socialmente como subalterno. A vista disso, historicamente, a comunidade LGBTQIA+, sensibilizada com situação de vulnerabilidade feminina, se associa àquela para unir forças contra os movimentos regressistas e, por esta e muitas outras razões, também acaba ocupando uma posição desprivilegiada.

Nesse patamar, considerando o contexto vivido pelo Brasil nos últimos anos, marcado pelo crescimento da desigualdade social, percebe-se a existência de um apelo mítico, impulsionado pelos grupos "contra-gênero", que defende a criação de remédios sociais miraculosos para solucionar questões complexas como distribuição de renda e promoção de respeito, cidadania, igualdade e sororidade. Dessa forma, visando a compreensão dessa linha da desigualdade, a qual ultrapassa a esfera econômica, é que se reitera a necessidade de serem analisados os escopos por trás da real efetivação estatal de garantias fundamentais, tais como a implementação de planos democráticos, incluindo pautas sobre direitos humanos, respeito à diversidade, liberdade, igualdade, políticas públicas e, especialmente, efetivação dos direitos sexuais, dos quais a comunidade LGBTQIA+ preza por concretização.

\section{Entendendo as estratégias discursivas conservadoras}

A análise dos documentos que contribuíram com os resultados desta pesquisa consistiu no levantamento dos principais grupos organizados e com inserção social relevante, que se utilizam do termo "ideologia de gênero" para deslegitimar as conquistas no campo da diversidade sexual. Foram analisados exatos 20 (vinte) documentos (descritos no Anexo A), os quais permitiram a realização de uma descrição discursiva, a partir de indicadores definidos, em torno do discurso sobre a existência de uma "ideologia de gênero" nos discursos dos grupos "pró-gênero". 
Optou-se por analisar o discurso firmado pelas seguintes instituições: Associação Nacional dos Juristas Evangélicos (ANAJURE), Movimento Brasil Livre (MBL), Instituto Plínio Correia de Oliveira (IPCO), Canção Nova, Partido Socialista Liberal (PSL) e Frente Evangélica do Congresso Nacional. Os detalhes com as informações dessas instituições podem ser visualizados no quadro abaixo:

Quadro 1 - Lista de instituições

\begin{tabular}{|c|c|c|}
\hline DENOMINAÇÃO & $\begin{array}{c}\text { NATUREZA } \\
\text { JURÍDICA }\end{array}$ & LINK DO SITE \\
\hline $\begin{array}{c}\text { Associação Nacional dos } \\
\text { Juristas Evangélicos } \\
\text { (ANAJURE) }\end{array}$ & Associação Privada & https://anajure.org.br/ \\
\hline $\begin{array}{c}\text { Comunidade Canção Nova } \\
\text { Organização } \\
\text { Religiosa }\end{array}$ & $\begin{array}{c}\text { https://comunidade.cancaon } \\
\text { ova.com/ }\end{array}$ \\
\hline $\begin{array}{c}\text { Instituto Plínio Corrêa de } \\
\text { Oliveira (IPCO) }\end{array}$ & Associação Privada & https://ipco.org.br/ \\
\hline $\begin{array}{c}\text { Movimento Brasil Livre } \\
\text { (MBL) }\end{array}$ & Associação Privada & https://mbl.org.br/ \\
\hline Partido Social Liberal (PSL) & Partido Político & https://psl.org.br/ \\
\hline
\end{tabular}

Fonte: os autores, 2020.

Essa seleção seguiu os seguintes critérios: a) possuir organização juridicamente constituída e canais oficiais de comunicação com seu público-alvo, de onde se pudesse extrair posicionamentos concretos (preferencialmente online); b) instituições que se auto identificassem com valores e ideais conservadores 8 ; c) manifestassem

8 É importante esclarecer que o termo "conservador" deve ser interpretado em seu sentido ideológico, isso porque os discursos analisados refletem consequências negativas que muitas vezes extrapolam as esferas jurídica e política. Além disso, é relevante compreender que os grupos, criteriosamente selecionados nesta pesquisa, se autodenominam "ideologicamente conservadores". 
posicionamentos públicos acerca dos temas abordados nesta pesquisa; d) atuassem nacionalmente; e) em alguns dos casos, foi considerada a capacidade de influenciar em processos judiciais e em decisões políticas, como no caso da Associação Nacional dos Juristas Evangélicos (ANAJURE), que atua frequentemente na condição de Amicus Curiae, perante a corte constitucional brasileira (STF), e do Partido Social Liberal (PSL) que elegeu diversos representantes políticos em todas as esferas federativas, tanto no executivo, quanto no legislativo.

A partir disso, foi realizada a sistematização desses dados, retirados dos sites oficiais dessas organizações, onde estão publicados diversos artigos e notas públicas, acerca de diversos temas, inclusive aqueles relacionados à "ideologia de gênero", homossexualidade e direitos da população LGBTQIA+. Após seleção, realizou-se a análise dos conteúdos desses documentos, sendo possível identificar a existência de quatro linhas argumentativas, com seus consequentes desdobramentos, elencados no quadro abaixo: 
Quadro 2 - Linhas argumentativas presentes nos documentos analisados vinculados aos direitos da população LGBTQIA+

\begin{tabular}{|c|c|}
\hline $\begin{array}{c}\text { LINHA } \\
\text { ARGUMENTATIVA }\end{array}$ & DESDOBRAMENTOS \\
\hline \multirow{4}{*}{$\begin{array}{l}\text { 1. Direito de apoiar e } \\
\text { propagar práticas } \\
\text { discriminatórias }\end{array}$} & $\begin{array}{l}\text { Simetria entre práticas discriminatórias e liberdade } \\
\text { de opinião ou liberdade religiosa. }\end{array}$ \\
\hline & Inexistência da homofobia e da transfobia. \\
\hline & $\begin{array}{l}\text { Responsabilizar práticas discriminatórias } \\
\text { homofóbicas seria perseguição religiosa. }\end{array}$ \\
\hline & $\begin{array}{l}\text { Simetria entre demanda por direitos e } \\
\text { reconhecimento da população LGBTQIA+ com } \\
\text { privilégios. }\end{array}$ \\
\hline \multirow{3}{*}{$\begin{array}{l}\text { 2. Deslegitimação e } \\
\text { difamação dos } \\
\text { movimentos LGBTQIA+ }\end{array}$} & $\begin{array}{l}\text { Existência de um "lobby" homossexual }{ }^{9} \text { que impõe } \\
\text { comportamentos que desvirtuam a família cristã. }\end{array}$ \\
\hline & $\begin{array}{l}\text { Simetria entre o movimento LGBTQIA+ com } \\
\text { regimes políticos totalitários ou ditatoriais. }\end{array}$ \\
\hline & $\begin{array}{l}\text { Relaciona as demandas por direitos dos } \\
\text { movimentos LGBTQIA+ à degradação moral e à } \\
\text { destruição da família. }\end{array}$ \\
\hline \multirow{2}{*}{$\begin{array}{l}\text { 3. Heteronormatividade } \\
\text { como único modelo de } \\
\text { comportamento "correto" }\end{array}$} & $\begin{array}{l}\text { Relação rígida entre sexo biológico e identidade de } \\
\text { gênero. }\end{array}$ \\
\hline & $\begin{array}{l}\text { Determinação de papéis sociais baseados no } \\
\text { gênero segundo parâmetros machistas. }\end{array}$ \\
\hline \multirow{2}{*}{$\begin{array}{l}\text { 4. Critérios processuais } \\
\text { para deslegitimar } \\
\text { demandas por direitos e } \\
\text { reconhecimento }\end{array}$} & $\begin{array}{l}\text { Decisões do STF que reconhecem direitos ferem a } \\
\text { separação dos poderes. }\end{array}$ \\
\hline & $\begin{array}{l}\text { Somente o Poder Legislativo possui atribuição para } \\
\text { criar norma jurídica. }\end{array}$ \\
\hline
\end{tabular}

Fonte: os autores, 2020.

${ }_{9} \mathrm{O}$ termo "lobby" diz respeito a uma atividade de pressão política, realizada por grupos organizados, que visam, a partir de objetivos definidos, exercer influência repressiva sobre o governo. No contexto a que se refere, "lobby homossexual" diz respeito aos movimentos progressistas que lutam em favor dos direitos da população LGBTQIA+, mas que acabam sendo taxados de desproporcionais, imperativos e categóricos, por grupos ideológico conservadores. 
Para que seja possível uma melhor visualização e compreensão desses dados, o Gráfico 1 ilustra quantitativamente o número de documentos conforme a linha argumentativa mapeada:

Gráfico 1: Quantidade de documentos segundo a linha argumentativa mapeada

1. Direito de apoiar e propagar práticas discrimin atórias

2. Deslegitimação e difamação dos movime ntos LGBTQIA+

3. Heteronormatividade como único modelo de comportamento "correto".

4. Critérios processuais para deslegitimar demandas por direitos e reconhecimento.

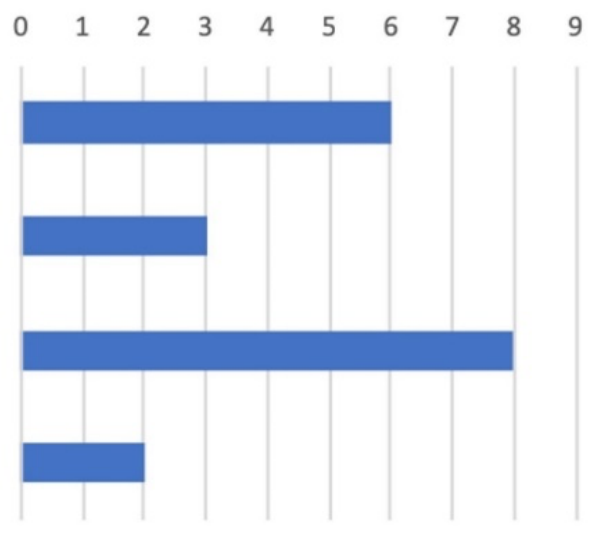

Fonte: os autores, 2020.

Há dois argumentos que se destacam, sendo o primeiro relacionado à existência de uma hierarquia relativa à orientação sexual e o segundo, relativo a uma "confusão" argumentativa que afirma ser liberdade de manifestação do pensamento apoiar e propagar atitudes discriminatórias face à comunidade LGBTQIA+. Nos próximos itens, discutir-se-á essas linhas argumentativas.

Quando liberdade religiosa, discriminação e deslegitimação se encontram

No que tange à primeira linha argumentativa, verifica-se a existência de uma constante discursiva que canoniza o modo de vivência heteronormativo como sendo "superior", baseando-se apenas em uma única orientação "afetivo-sexual" possível ou correta. Com base nisso, sustentam o direito de propagar práticas discriminatórias como correlato ao direito à livre manifestação do pensamento e de crença. 
Esses discursos negam a existência de práticas homofóbicas ou transfóbicas, sob o fundamento de que socialmente os padrões éticos e morais sustentados pela fé justificariam essa prática como sendo mera manifestação de expressão religiosa, resultado da pluralidade de discursos ou mera liberdade de opinião. Essa linha argumentativa pode ser verificada em 6 (seis) documentos analisados (DOCs. 1, 6, 8, 9, 15 e 19, Quadro 3, presente no Anexo A).

É uma linha argumentativa que utiliza fundamentos religiosos e valores morais restritivos para legitimar preconceitos, situação que exclui a diversidade do campo dialógico, de forma a subverter titulares do "direito" de violar direitos pessoas com comportamentos não heteronormativos sem ter que se responsabilizar pela discriminação.

De modo complementar à primeira, a segunda linha argumentativa trabalha com um discurso deslegitimador e difamatório dos movimentos LGBTQIA+. Sem apresentar evidências concretas, esses discursos afirmam a existência de uma suposta manipulação sobre a população acerca dos temas sobre a homossexualidade. Relacionam a discussão pública e a representatividade da população LGBTQIA+ na mídia, como sendo uma espécie de manipulação ideológica para legitimar uma suposta ascensão da denominada "ditadura homossexual", comparada literalmente aos "regimes totalitários". O Instituto Plínio Corrêa de Oliveira (IPCO) assevera que o "homossexualismo" [sic] censura e impõe uma espécie de "dogma laico" contra a Moral Católica, no qual os transgressores deveriam se sujeitar até mesmo à pena de prisão. O IPCO, bem como as demais instituições, entende que a criminalização da homofobia representa um passo na debilitação do senso moral e na desconstrução da família e que essa possível punibilidade, em razão da prática de discriminação, são perseguições àqueles que não aderem à suposta "ideologia homossexual".

Sendo assim, a impressão que se tem é de que esses grupos possuem o "dever" de incentivar a proteção do instituto familiar, em 
razão de uma aparente publicidade ofensiva dos chamados poderosos "lobbys" homossexuais, que atuam na mente dos indivíduos, como forma de manipulá-los. Esses argumentos foram mapeados em 3 (três) dos 20 (vinte) documentos analisados, todos publicados pelo IPCO (DOCs. 1, 2 e 3, Quadro 3, presente no Anexo A).

No entanto, contrariamente ao que essa linha argumentativa afirma, em nenhum momento o movimento LGBTQIA+ quis impor regras, tampouco obrigar as pessoas a seguirem os mesmos pensamentos defendidos por ele. Ao contrário do que essas instituições alegam, o que o movimento espera é empatia pela história vivida por cada um de seus integrantes. Espera-se, inclusive, que pessoas de diferentes contextos sociais possam participar livremente de debates abertos a diálogos democráticos, respeitosos e sem qualquer tipo de preconceito.

Não há, portanto, qualquer intenção deliberada de forçar comportamentos e ideias a ninguém, mas de expor fragilidades, diferenças, histórias de vida e desigualdades, sem que isso resulte em julgamento social, tampouco em violência física, visando indispensavelmente a efetivação de tratamento igualitário e digno a qualquer pessoa.

Heteronormatividade e diversidade sexual: quando um único código de conduta é excludente

Do mesmo modo, como já aludido anteriormente, percebe-se ainda uma terceira linha de raciocínio, que se consolida em torno da ideia de que a heterossexualidade é o único modelo de comportamento afetivo-sexual "correto". Para esses grupos há uma tendência em desconsiderar qualquer reconhecimento à construção social do gênero e em reconhecer tão somente as diferenciações biológicas entre homens e mulheres, colocando-as, inclusive, em uma posição inferior à masculina. Essa argumentação também sustenta que homens e mulheres são "naturalmente" prontos para o exercício de funções sociais pré- 
determinadas por seu sexo biológico, situação essa que define comportamentos e justifica desigualdades socialmente construídas. Nessa linha argumentativa, há ainda um esforço empreendido para descaracterizar a cientificidade dos estudos de gênero, com afirmações de que existem lacunas, incongruências e contradições em suasteorias.

Entretanto, tais argumentos sequer problematizam ou definem métodos científicos das ciências biológicas e sociais, esses, inclusive, desconsideram as inúmeras pesquisas de campo, de diversas áreas de conhecimento, que quantificam e qualificam dados sobre desigualdades e violências baseadas no gênero.

Ao tentar desqualificar os estudos de gênero, alegando desprovimento de cientificidade, observa-se que as afirmações realizadas nessa linhagem não possuem qualquer fundamentação científica e que esses discursos são construídos em torno do imaginário de uma suposta ameaça às crianças e famílias heteroafetivas. Tais discursos veiculam uma espécie de "pânico moral", baseado em crenças e suposições que não refutam os estudos de gênero, especialmente na parte que descrevem e analisam a diversidade sexual, que demonstram justamente que há um enorme esforço de se normatizar e enquadrar a diversidade sexual em nossa sociedade, situação essa que gera exclusão, violência e adoecimento de pessoas que não se "encaixam" nos padrões impostos. Negam também diversos estudos que demonstram que uma adequada educação sexual de crianças e jovens previne diversos problemas sociais que enfrentamos hoje, tais como abuso sexual infantil, gravidez na adolescência, transmissão de DSTs, violência doméstica, dentre outros. Essa linha argumentativa foi a de maior incidência nos documentos analisados, encontrada em 8 (oito) dos 20 (vinte) documentos analisados (Docs. 4, 5, 7, 11, 12,13, 14 e 15 do Anexo A).

Por fim, também vale dizer que foi possível extrair desses discursos uma linha argumentativa processual. Nela, a fundamentação está voltada à inexistência de ofensa à laicidade estatal quando buscam contrapor estudos de gênero e fundamentos religiosos e à afirmação de 
que a conduta do STF em criminalizar a homotransfobia teria extrapolado sua função típica, violando o princípio da separação dos poderes ao legislar sobre matéria que seria de competência do Poder Legislativo, o qual, em tese, teria atribuição para estabelecer tipos penais. Do mesmo modo, esses grupos também tentam enfrentar regras de conduta ética que impedem o registro profissional de advogados que atentem contra a comunidade LGBTQIA+10. Nessa linha, 2 (dois) documentos dentre os 20 (vinte) analisados, abordam essa linha argumentativa (DOCs 1,2 e 6 do Anexo 1).

\section{As percepções constitucionais e os posicionamentos firmados pela Corte Internacional de Direitos Humanos (CIDH) sobre o tema da diversidade sexual}

O que se percebe, na verdade, é que esses discursos atacam o reconhecimento de direitos humanos largamente reconhecidos pelo campo jurídico, assim como simplificam e reduzem, a um biologicismo indemonstrável, a problematização de comportamentos e relações humanas complexas.

Acerca dos discursos conservadores, López afirma existir um apelo a argumentos centrados num nacionalismo paradoxal, onde as políticas de reconhecimento de direitos LGBT são consideradas "imposições" de organizações internacionais que querem estabelecer a "ideologia de gênero" (LÓPEZ, 2020, p. 11). Essas percepções foram extraídas dos documentos que afirmam existir uma "ditadura" ou "lobby" homossexual no Brasil (DOCs. 1, 6, 8, 9, 15 e 19, Quadro 3, presente no Anexo A).

Em defesa ao "nacionalismo" e à cultura heteronormativa, esses grupos ideológico conservadores protestam contra decisões governamentais de países da América Latina, que tentam ou tentaram

10 Súmula 11 publicada pelo Conselho Pleno da OAB, no dia 10/06/2019. Disponível em: <https://www.oab.org.br/Content/pdf/sumulas/sumula-11-2019-COP.pdf>. Acesso em 18 jul 2020. 
implementar planos educativos com perspectivas de gênero, educação sexual e reprodutiva. López (2020, p. 14) também pontua que em diversos países os discursos em torno da ideologia de gênero:

limitaram a implementação de políticas públicas em matéria de direitos sexuais, principalmente aquelas relacionadas aos manuais de educação, tornando-se resistências efetivas com consequências materiais frente aos direitos das minorias sexuais. Em casos como o Paraguai, Panamá, Bolívia, Peru, onde os direitos LGBT não avançaram significativamente, a reação conservadora foi imposta como estratégia preventiva para resistir ao reconhecimento de direitos como o matrimônio igualitário e a adoção homoparental. Finalmente, é importante destacar que o discurso da ideologia de gênero não só limita os direitos da população LGBT, mas também (e principalmente) os direitos das mulheres, na medida em que as políticas públicas de educação sexual são o pilar fundamental para seu desenvolvimento pessoal, com autonomia e liberdade.

Ireneu e Oliveira afirmam que nas últimas duas décadas o Estado brasileiro tem implementado políticas públicas e reconhecido direitos para o público LGBTQIA+ no campo da saúde, do reconhecimento como entidade familiar, dos direitos sociais ao trabalho, previdência e do combate à LGBTfobia e transfobia (IRINEU; OLIVEIRA, 2019, p. 10 e 11). Ocorre que a implementação dessas políticas públicas tem sofrido ataque desses grupos organizados. No entanto, seus fundamentos andam na contramão de estudos que demonstram que a inobservância ou omissão de líderes políticos, quanto ao incentivo ao tratamento igualitário dos cidadãos, no que se refere às igualdades raciais e sexuais, prejudicam o desenvolvimento educacional e econômico do país.

Nessa perspectiva, a Corte Interamericana de Direitos Humanos $(\mathrm{CIDH})$ publicou a Opinião Consultiva n. ${ }^{\circ}$ 24, em razão de solicitação realizada pelo governo da Costa Rica, para que a Corte interpretasse as garantias estabelecidas à comunidade LGBTQIA+ pela Convenção 
Americana de Direitos Humanos, no que tange especialmente ao reconhecimento da alteração do nome social, acompanhando a identidade de gênero de cada indivíduo. O documento tratou, ainda, acerca do reconhecimento dos direitos econômicos originados a partir de uma união homoafetiva (CIDH, 2017).

Assim, compulsando o referido parecer, percebeu-se ter sido consolidado o posicionamento jurisprudencial firmado pela Corte nos últimos anos, de que a orientação sexual e identidade de gênero são garantias resguardadas pelo Pacto de San José da Costa Rica, uma vez que, no entendimento daquela Comissão, esses direitos estão interligados às garantias de liberdade e autodeterminação. Ademais, o entendimento da Corte obriga os Estados-Membros da Organização dos Estados Americanos a efetuarem alterações normativas e institucionais para o reconhecimento pleno, bem como para o exercício dos direitos da população LGBTQIA+.

Constata-se esses grupos variam seu rol de fundamentos entre argumentações de cunho religioso, teses biológicas, filosóficas e judiciais. A tentativa de criar princípios e direitos que considerem a diversidade e a complexidade das relações humanas é um modo de mitigar relações historicamente opressoras a certos grupos, vulnerabilizados pela sua condição. Por isso, garantir uma legislação e a aplicação do direito revestidas de impessoalidade e baseadas na dignidade humana, como preconiza a Constituição Federal de 1988, é um ato de resistência e de inclusão.

Desse modo, entende-se como evidentes as violações lançadas publicamente por essas instituições, pois esses discursos visam, muitas vezes, tão somente a deslegitimação de categorias complexas de direitos humanos, tais como os direitos sexuais, não revelando integralmente a realidade brasileira, uma vez que são proferidos por instituições que ocupam posições privilegiadas e estão desprovidas de credibilidade para questionar realidades diversas daquelas que entendem como 
moralmente aceitáveis, bem como desmantelar valores, garantias, teses, entendimentos e decisões judiciais favoráveis às minorias sociais.

\section{Considerações finais}

É notório que o discurso da "ideologia de gênero" provocou, na última década, grande impacto no cenário político brasileiro, especialmente no que tange às discussões de implementação de programas educacionais inclusivos e à efetividade das políticas públicas voltadas à promoção da igualdade de gênero. Embora esse fato tenha desestabilizado a manutenção de direitos das minorias que a presente pesquisa faz referência, em razão da emersão de discursos de ódio face à "emancipação sexual" dos indivíduos e do menor sinal de surgimento de quaisquer políticas públicas que beneficiem a comunidade LGBTQIA+, foi possível perceber a idealização de novas estratégias de enfrentamento a problemas sociais e discursivos articulados pelos grupos "contra-gênero". Acredita-se que isso decorre, basicamente, do avanço comunicacional e democrático proporcionado pela internet, bem como da abertura dialógica de pessoas que, sensibilizadas com a causa, cedem seus lugares de fala a vozes desprivilegiadas.

Nessa mesma perspectiva, também foi possível constatar que as estratégias discursivas utilizadas pelas instituições analisadas se consolidam basicamente em acusar os movimentos "pró-gênero" de exercerem uma influência negativa quando esses, teoricamente, incentivam a constituição de relações homoafetivas (incluindo o casamento), a legalização do aborto e a sustentação da "ideologia de gênero", tão somente com a finalidade de difamá-los. Desse modo, em repressão a essas suposições, os movimentos conservadores, "ameaçados" por essa nova realidade, fortalecem a "onda conservadora", sentindo-se no dever de "proteger" tradições e padrões heteronormativos que, embora ultrapassados, inevitavelmente, refletem em decisões proferidas por quaisquer dos três poderes da nação (Executivo, Legislativo e Judiciário) e em atos de violência física, 
fácil e irresponsavelmente omitidos e/ou desconsiderados em momento conveniente para investigação ou responsabilização cível e penal.

Nessa continuidade, também se percebe que a estratégia de "pânico moral" nesses discursos está presente em quase todas as instituições analisadas, à medida que temas como diversidade, orientação sexual, identidade de gênero e educação sexual passaram a ser interpretados como problemas e ameaças sociais que necessitam de intervenção imediata para contenção e não como resultado da pluralidade humana, de maneira que possam ser valorizados socialmente.

Também se constata que inexistem evoluções, em termos argumentativos, que possam continuar sustentando, com expressividade, quaisquer posicionamentos que desvalorizem e deslegitimem a diversidade e o direito à igualdade de tratamento, constitucionalmente garantido pelo art. $5^{\circ}$, da Constituição Federal de 1988. Isso porque, além de realizarem publicações cientificamente infundadas, inexistem quaisquer esforços por parte dessas instituições no sentido de que sejam realizados investimentos em estudos íntegros, para que deixem de mascarar preconceitos e passem a compreender a multiplicidade de comportamentos humanos, abrindo margens às discussões democráticas.

Finalmente, o que se observa são recorrentes omissões, por parte dessas instituições, frente ao aumento de crimes contra a dignidade da pessoa humana, bem como replicações inverídicas e inércia discursiva frente a esses mesmos problemas, por parte das altas classes conservadoras, que nada fazem além de tentar calar os movimentos feminista e LGBTQIA+, ignorando sem qualquer temor o direito à diversidade e à vida digna de cada ser humano que os integram.

\section{Referências}


ALMEIDA, Ronaldo de. A onda quebrada - evangélicos e conservadorismo. Cadernos Pagu, Campinas, n. 50, 2017. Disponível em: $\quad$ http: / / www.scielo.br / scielo.php?pid=S0104$83332017000200302 \&$ script=sci_abstract\&tlng=pt. Acesso em: 01 abr 2020.

BUTLER, Judith. Problemas de gênero. Feminismo e subversão de identidade. Tradução de Renato Aguiar. Rio de Janeiro: Civilização Brasileira, 2003.

CARVALHO, Maria Eulina. Gênero: O que é e o que não é ideologia? Disponível em: <http://www.ufpb.br/escolasplurais/contents/noticias/didaticos/ o-que-e-e-o-quenao-e-ideologia-degenero/Gnerooqueeoquenoideologia4.pdf>. Acesso em: 07 abr. 2020.

CONNEL, Robert. Políticas da masculinidade. Educação e Realidade, Porto Alegre, v. 20, n. 2, p. 185-206, jul./dez., 1995. Disponível em: <https://seer.ufrgs.br/educacaoerealidade/article/view/71725/406 71>. Acesso em: 20 abr. 2020.

CONNELL, Raewyn; PEARSE, Rebecca. Gênero: uma perspectiva global. 3. ed. São Paulo: Versos, 2015.

CORREA, Sonia; PETCHESKY, Rosalind. Direitos sexuais e reprodutivos: uma perspectiva feminista. Physis, Rio de Janeiro, v. 6, n. 1-2, p. 147-177, 1996. Disponível em: <http:/ / www.scielo.br/scielo.php?script=sci_arttext\&pid=S010373311996000100008\&lng=en\&nrm=iso>. Acesso em: 15 out. 2020.

CORTE INTERAMERICANA DE DIREITOS HUMANOS. Parecer Consultivo OC-24/17: identidade de gênero, igualdade e não discriminação a casais do mesmo sexo. Disponível em: <http://www.corteidh.or.cr/docs/opiniones/seriea_24_por.pdf>. Acesso em: 19 jul. 2020.

DOMBROWSKI, Osmir. Conservador nos costumes e liberal na economia: liberdade, igualdade e democracia em Burke, Oakeshott e Hayek. Revista Katálysis, v. 23, n. 2, p. 223-234. Disponível em: <http:/ / www.scielo.br/scielo.php?script=sci_arttext\&pid=S141449802020000200223\&lng=pt\&nrm=iso>. Acesso em: 21 jul. 2020. 
ESCOLA SUPERIOR DO MINISTÉRIO PÚBLICO DA UNIÃO. Dicionário de Direitos Humanos: gênero, 2006. Disponível em: $<$ https:/ / escola.mpu.mp.br/dicionario/tikiindex.php?page=G\%C3\%AAnero>. Acesso em: 20 abr 2020.

FERREIRA, Guilherme Gomes. Conservadorismo, fortalecimento da extrema-direita e a agenda da diversidade sexual e do gênero no Brasil contemporâneo. Lutas Sociais, v. 20, n. 36, 2016. Disponível em: <https://www.ifg.edu.br/attachments/article/7536/Conservadoris mo, $\% 20$ fortalecimento $\% 20 \mathrm{da} \% 20$ extremadireita $\% 20$ e $\%$ 20a \%20agenda $\% 20$ da $\% 20$ diversidade $\% 20$ sexual $\% 20$ e $\%$ $20 \mathrm{de} \% 20 \mathrm{~g} \%$ C3\% AAnero $\% 20$ no $\% 20$ Brasil $\% 20$ contempor $\%$ C3\%A2ne o\% 20\%E2\%80\%93\%20Guilherme\%20Ferreira.pdf>. Acesso em: 11 out. 2020.

GALVÃO, Jane. Aids no Brasil: a agenda de construção de uma epidemia. Rio de Janeiro/São Paulo, ABIA/Editora 34, 2000.

GAMA, Marina de Mello. El discurso de odio del gobierno Bolsonaro y la banalidade del mal. Ars Iuris Salmanticensis, Espanha: Universidad de Salamanca, v. 7, n. 2, 2019, p. 15-21 Disponível em: <https://dialnet.unirioja.es/servlet/articulo?codigo $=7273487>$. Acesso em: 20 abr. 2020.

HARVEY, David. Condição pós-moderna: uma pesquisa sobre as origens da mudança cultural. São Paulo: Edições Loyola, 2006.

INTERDONATO, Giann Lucca; QUEIROZ, Marisse Costa de. "Transidentidade": a transexualidade e o ordenamento jurídico. Curitiba: Appris, 2017.

IRINEU, Bruna Andrade; OLIVEIRA, Brendhon Andrade. Um estudo sobre as políticas de trabalho, emprego e renda para população LGBT no Brasil e na Argentina. Anais do $16^{\circ}$ Congresso Brasileiro de Assistentes Sociais. v. 16. n. 1. Brasília: 2019. Disponível em: <https://broseguini.bonino.com.br/ojs/index.php/CBAS/article/v iew/139>. Acesso em: 24 jul 2020.

JUNQUEIRA, Rogério Diniz. “Ideologia de gênero": a gênese de uma categoria política reacionária ou: a promoção dos direitos humanos se tornou uma "ameaça à família natural"? in Debates contemporâneos sobre Educação para a sexualidade. Organizado por Paula Regina 
Costa Ribeiro e Joanalira Corpes Magalhães. Rio Grande: ed. da FURG, 2017.2 Disponível em: <http:/ / repositorio.furg.br/bitstream/handle/1/7097/debates_con temporaneos_educac ao_sexualidade.pdf?sequence=1>. Acesso em: 13 abr 2020.

LIMA, George Marmelstein. Críticas à teoria das gerações (ou mesmo dimensões) dos direitos fundamentais. Revista Jus Navigandi, Teresina, ano 8, n. 173, 26 dez. 2003. Disponível em: https://jus.com.br/artigos/4666. Acesso em: 10 jul. 2020.

LÓPEZ, Jairo. La "ideología de género" y las resistencias frente a los derechos LGBT en América Latina in Género, Feminismo y Derechos Humanos: reflexiones desde el Sur. Equador: Universidad de Cuenca, 2020.

Disponível

em:

<https://www.researchgate.net/profile/Jairo_Lopez_Pacheco/publ ication/342610857_La_ideologia_de_genero_y_las_resistencias_frent e_a_los_derechos_LGBT_en_Am

erica_Latina/links/5efccde7299bf18816f652e3/La-ideologia-degenero-y-las- resistencias-frente-a-los-derechos-LGBT-en-AmericaLatina.pdf>. Acesso em: 24 jul 2020.

MIGUEL, Luis Felipe. Da “doutrinação marxista" à "ideologia de gênero": Escola Sem Partido e as leis da mordaça no parlamento brasileiro. Revista Direito e Práxis, v. 7, n. 15, p. 590-621, 2016.

MINISTÉRIO DOS DIREITOS HUMANOS. Plano Nacional de Educação em Direitos Humanos. Brasília: Secretaria Especial dos Direitos Humanos, 2018. Disponível em: <https://www.gov.br/mdh/pt$\mathrm{br} /$ navegue-por-temas/educacao-em-direitos-humanos/planonacional-de-educacao-em-direitos-humanos>. Acesso em: 17 ago 2020.

NATIVIDADE, Marcelo; OLIVEIRA, Leandro de. Sexualidades ameaçadoras: religião e homofobia(s) em discursos evangélicos conservadores. Sexualidad, Salud y Sociedad-Revista Latinoamericana, n. 2, p. 121-161, 2009.2 Disponível em: <https://www.redalyc.org/pdf/2933/293322969007.pdf>. Acesso em: 13 abr.2020.

ONU. Declaração e Plataforma de Ação da IV Conferência Mundial Sobre a Mulher.

Pequim, 1995. Disponível em: 
<http:/ / www.onumulheres.org.br/wpcontent/uploads/2014/02/declaracao_pequim.pdf>. Acesso em: 15 out. 2020.

ONU. Declaração e Programa de Ação de Viena. Conferência Mundial Sobre Direitos Humanos. Viena, 1993. Disponível em: <http://www.direitoshumanos.usp.br/index.php/Sistema-Global.Declara\%C3\%A7\%C3\%B5es-e-Tratados-Internacionais-deProte \%C3\%A7\%C3\%A3o/ declaracao-e-programa-de-acao-deviena.html>. Acesso em: 15 out. 2020.

ONU. Plataforma do Cairo: Relatório da Conferência Internacional sobre População e Desenvolvimento. Cairo, 1994. Disponível em: <http://www.unfpa.org.br/Arquivos/relatorio-cairo.pdf>. Acesso em: 15 out. 2020.

PEDRO, Joana Maria. Narrativas fundadoras do feminismo: poderes e conflitos (1970-1978). Rev. Bras. Hist., São Paulo, v. 26, n. 52, p. 249-272, dez. 2006.

Disponível em: <http:/ / www.scielo.br/scielo.php?script=sci_arttext\&pid=S010201882006000200011\&lng=en\&nrm=iso >. Acesso em: 12 abr. 2020.

PIOVESAN, Flavia. Temas de Direitos Humanos. São Paulo: Max Limonad, 2003.

SALIH, S. Judith Butler e a Teoria Queer. Tradução de Guacira Lopes Louro. Belo Horizonte: Autêntica, 2013.

SCHIOCCHET, Taysa. Marcos normativos dos direitos sexuais: uma perspectiva emancipatória. In: BRAUNER, Maria Claudia Crespo (org.). Biodireito e gênero. Ijui: Unijui, 2007. p. 61-106. Disponível em: <https://unisinos.academia.edu/TaysaSchiocchet>. Acesso em: 15 out. 2020.

SCOTT, Joan. Gênero: uma categoria útil de análise histórica. Educação \& Realidade, Porto Alegre, v. 20, n. 2, p. 71-99, 1995.

SCOTUS. Masterpiece Cakeshop, Ltd., et al. v. Colorado Civil Rights Commission et al: opinion of the court, 2018. Disponível em: < https://www.supremecourt.gov/opinions/17pdf/16-111_j4el.pdf>. Acesso em: 24 jul 2020.

SILVA, Sergio Gomes da. Masculinidade na história: a construção cultural da diferença entre os sexos. Psicol. cienc. prof., Brasília, v. 
20, n. 3, pp. 8-15, set. 2000 Disponível em: <http:/ / pepsic.bvsalud.org/scielo.php?script=sci_abstract\&pid=S14 14-98932000000300003>. Acesso em: 01 abr 2020.

SOIHET, R. História das mulheres e história de gênero: um depoimento. Cadernos Pagu, n.11, pp. 77-87, 2013. Disponível em: $<$ https://periodicos.sbu.unicamp.br/ojs/index.php/cadpagu/articl e/view/8634464/2388>. Acesso em: 20 abr 2020.

TEIXEIRA, Antonio Claudio Engelke Menezes. A vanguarda conservadora: aspectos políticos e simbólicos do movimento LGBT. Desigualdade E Diversidade - Revista de Ciências Sociais da PUC-Rio, n. 7, p. 63-80, 2010. Disponível em: $<$ http:/ / desigualdadediversidade.soc.pucrio.br/media/artigo3_7.pdf>. Acesso em: 20 abr. 2020.

UNESCO. International technical guidance on sexuality education: an evidence- informed approach. rev. ed. Paris: United Nations Educational, Scientific and Cultural Organization, 2018. Disponível em: <https://www.unaids.org/sites/default/files/media_asset/ITGSE_ en.pdf>. Acesso em: 24 jul. 2020. 


\section{ANEXO A - Documentos analisados}

Quadro 3 - Lista de documentos analisados com link de acesso

\begin{tabular}{|c|c|c|c|c|c|}
\hline ORDEM & TÍTULO & INSTITUIÇÃO & TIPO & DATA & LINK PARA O DOCUMENTO \\
\hline DOC. 1 & $\begin{array}{l}\text { A homofobia, o STF, a religião e a opinião de renomados } \\
\text { cientistas }\end{array}$ & $\mathrm{IPCO}$ & $\begin{array}{l}\text { Artigo } \\
\text { Público }\end{array}$ & $19 / 02 / 2019$ & $\begin{array}{l}\text { https:/ /ipco.org.br/a-homofobia-o-stf-a-religiao-e-a- } \\
\text { opiniao-de-renomados-cientistas/ }\end{array}$ \\
\hline DOC. 2 & $\begin{array}{l}\text { STF, Homofobia e a palavra-talismã que assassina o } \\
\text { senso moral }\end{array}$ & IPCO & $\begin{array}{l}\text { Artigo } \\
\text { Público }\end{array}$ & $25 / 02 / 2019$ & $\begin{array}{l}\text { https://ipco.org.br/stf-homofobia-e-a-palavra-talisma- } \\
\text { que- assassina-o-senso-moral/ }\end{array}$ \\
\hline DOC. 3 & STF pode tornar crime defender a Moral Católica & IPCO & $\begin{array}{l}\text { Artigo } \\
\text { Público }\end{array}$ & $21 / 02 / 2019$ & $\begin{array}{l}\text { https://ipco.org.br/stf-pode-tornar-crime-defender-a- } \\
\text { moral-catolica/ }\end{array}$ \\
\hline DOC. 4 & $\begin{array}{l}\text { “Brian ou Brenda?": uma história distorcida em prol da } \\
\text { ideologia de gênero }\end{array}$ & IPCO & $\begin{array}{l}\text { Artigo } \\
\text { Público }\end{array}$ & $01 / 10 / 2019$ & $\begin{array}{l}\text { https://ipco.org.br/brian-ou-brenda-uma-historia- } \\
\text { distorcida-em-prol-da-ideologia-de-genero/ }\end{array}$ \\
\hline DOC. 5 & Meninos vestem azul, meninas vestem rosa? & $\mathrm{IPCO}$ & $\begin{array}{l}\text { Artigo } \\
\text { Público }\end{array}$ & $11 / 01 / 2019$ & $\begin{array}{l}\text { https:/ /ipco.org.br/meninos-vestem-azul-meninas- } \\
\text { vestem- rosa/ }\end{array}$ \\
\hline DOC. 6 & $\begin{array}{l}\text { ANAJURE emite NOTA PÚBLICA sobre a tese firmada } \\
\text { no julgamento da ADO 26, relativa à criminalização da } \\
\text { Homo/Transfobia }\end{array}$ & ANAJURE & $\begin{array}{l}\text { Nota } \\
\text { Pública }\end{array}$ & $11 / 01 / 2019$ & $\begin{array}{l}\text { https://anajure.org.br/anajure-emite-nota-publica- } \\
\text { sobre-a- tese-firmada-no-julgamento-da-ado-26- } \\
\text { relativa-a- criminalizacao-da-homotransfobia/ }\end{array}$ \\
\hline DOC. 7 & $\begin{array}{l}\text { ANAJURE lança Nota Pública sobre parecer da AGU } \\
\text { acerca da ideologia de gênero nas leis estaduais e } \\
\text { municipais }\end{array}$ & ANAJURE & $\begin{array}{l}\text { Nota } \\
\text { Pública }\end{array}$ & $04 / 09 / 2019$ & $\begin{array}{l}\text { https:/ / anajure.org.br/anajure-lanca-nota-publica- } \\
\text { sobre- parecer-da-agu-acerca-da-ideologia-de-genero- } \\
\text { nas-leis- estaduais-e-municipais/ }\end{array}$ \\
\hline DOC. 8 & $\begin{array}{l}\text { ANAJURE lança NOTA PÚBLICA em apoio à suspensão } \\
\text { de vestibular destinado exclusivamente a indivíduos } \\
\text { transgêneros }\end{array}$ & ANAJURE & $\begin{array}{l}\text { Nota } \\
\text { Pública }\end{array}$ & $17 / 07 / 2019$ & $\begin{array}{l}\text { https://anajure.org.br/anajure-lanca-nota-publica-em- } \\
\text { apoio-a-suspensao-de-vestibular-destinado- } \\
\text { exclusivamente-a-individuos-transgeneros/ }\end{array}$ \\
\hline DOC. 9 & $\begin{array}{l}\text { ANAJURE emite Nota Pública sobre a orientação do } \\
\text { governo brasileiro sobre o uso do termo "Gênero" }\end{array}$ & ANAJURE & $\begin{array}{c}\text { Nota } \\
\text { Pública }\end{array}$ & $28 / 06 / 2019$ & $\begin{array}{l}\text { https:/ / anajure.org.br/anajure-emite-nota-publica- } \\
\text { sobre-a- orientacao-do-governo-brasileiro-sobre-o-uso- } \\
\text { do-termo- } \\
\text { genero/ }\end{array}$ \\
\hline DOC. 10 & $\begin{array}{l}\text { ANAJURE emite Nota Pública referente a Súmula do } \\
\text { Conselho Federal da OAB sobre violência contra pessoas }\end{array}$ & ANAJURE & $\begin{array}{l}\text { Nota } \\
\text { Pública }\end{array}$ & $13 / 06 / 2019$ & $\begin{array}{l}\text { https:/ / anajure.org.br/anajure-emite-nota-publica- } \\
\text { referente-a-sumula-do-conselho-federal-da-oab-sobre- }\end{array}$ \\
\hline
\end{tabular}




\begin{tabular}{|c|c|c|c|c|c|}
\hline & LGBTQI+ & & & & violencia-contra-pessoas-lgbtqi/ \\
\hline DOC.11 & $\begin{array}{l}\text { ANAJURE e entidades educacionais parceiras emitem } \\
\text { Nota Pública sobre caso da escola Adventista que } \\
\text { englobou o tema da homossexualidade em avaliação } \\
\text { escolar }\end{array}$ & ANAJURE & $\begin{array}{l}\text { Nota } \\
\text { Pública }\end{array}$ & $20 / 11 / 2019$ & $\begin{array}{l}\text { https://anajure.org.br/anajure-e-entidades- } \\
\text { educacionais- parceiras-emitem-nota-publica-sobre- } \\
\text { caso-da-escola-adventista-que-englobou-o-tema-da- } \\
\text { homossexualidade- em-avaliacao-escolar/ }\end{array}$ \\
\hline DOC. 12 & Ideologia de gênero e a desconstrução da família & CANÇÃO NOVA & $\begin{array}{l}\text { Artigo } \\
\text { Público }\end{array}$ & 2019 & $\begin{array}{l}\text { https:// formacao.cancaonova.com/atualidade/ideolog } \\
\text { iade genero/ideologia-de-genero-e-a-desconstrucao-da- } \\
\text { familia/ }\end{array}$ \\
\hline DOC. 13 & Ideologia de gênero: as crianças me inspiraram a escrever & CANÇÃO NOVA & $\begin{array}{l}\text { Artigo } \\
\text { Público }\end{array}$ & 2019 & $\begin{array}{l}\text { https://formacao.cancaonova.com/atualidade/ideolog } \\
\text { iade genero/ideologia-de-genero-criancas-inspiraram- } \\
\text { escrever/ }\end{array}$ \\
\hline DOC. 14 & A hilária Ideologia de Gênero & CANÇÃO NOVA & $\begin{array}{l}\text { Artigo } \\
\text { Público }\end{array}$ & 2019 & $\begin{array}{l}\text { https://formacao.cancaonova.com/atualidade/ideolog } \\
\text { iade genero/hilaria-ideologia-de-genero/ }\end{array}$ \\
\hline DOC. 15 & Como lidar com o meu filho homossexual? & CANÇÃO NOVA & $\begin{array}{l}\text { Artigo } \\
\text { Público }\end{array}$ & 2019 & $\begin{array}{l}\text { https://formacao.cancaonova.com/afetividade-e- } \\
\text { sexualidade/afetividade-feminina/como-lidar-com-o- } \\
\text { meu-filho-homossexual/ }\end{array}$ \\
\hline DOC. 16 & $\begin{array}{l}\text { Em Marcha para Jesus, Bolsonaro afirma que ideologia de } \\
\text { gênero é "do capeta" }\end{array}$ & MBL & $\begin{array}{l}\text { Artigo } \\
\text { Público }\end{array}$ & $10 / 08 / 2019$ & $\begin{array}{l}\text { https://mblnews.org/nacional/em-marcha-para-jesus- } \\
\text { bolsonaro-afirma-que-ideologia-de-genero-e-do-capeta }\end{array}$ \\
\hline DOC. 17 & O Escola Sem Partido morreu, mas passa bem & MBL & $\begin{array}{l}\text { Artigo } \\
\text { Público }\end{array}$ & $22 / 07 / 2019$ & $\begin{array}{l}\text { https://mblnews.org/colunista/_gutozacarias/o- } \\
\text { escola- sem-partido-morreu-mas-passa-bem }\end{array}$ \\
\hline DOC. 18 & $\begin{array}{l}\text { Resposta ao nojento artigo de Jean Wyllys sobre Karol } \\
\text { Eller }\end{array}$ & MBL & $\begin{array}{l}\text { Artigo } \\
\text { Público }\end{array}$ & $18 / 12 / 2019$ & $\begin{array}{l}\text { https://mblnews.org/nacional/resposta-ao-nojento- } \\
\text { artigo- de-jean-wyllys-sobre-karol-eller }\end{array}$ \\
\hline DOC. 19 & Em que acreditamos & PSL & $\begin{array}{l}\text { Artigo } \\
\text { Público }\end{array}$ & Sem data & https://psl.org.br/?page_id=27 \\
\hline DOC. 20 & Novo estatuto do PSL & PSL & $\begin{array}{l}\text { Artigo } \\
\text { Público }\end{array}$ & $02 / 06 / 2020$ & https://psl.org.br/?p=2183 \\
\hline
\end{tabular}

Fonte: os autores, 2020 